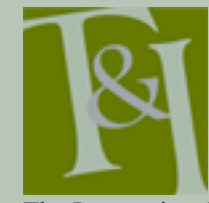

The International Journal for Translation \& Interpreting Research trans-int.org

\title{
Thrown in the deep end: Challenges of interpreting informal paramedic language
}

\author{
Ineke Crezee \\ Auckland University of Technology \\ icrezee@aut.ac.nz

\section{Lynn Grant} \\ Auckland University of Technology \\ lgrant@aut.ac.nz
}

DOI: 10.12807/ti.108202.2016.a01

\begin{abstract}
At the authors' university, interpreting pedagogies reflect the situated-learning theories proposed by Lave and Wenger (1991) and others especially in specialized areas such as health and legal interpreting. This paper reports on a project where health interpreting students in a language-neutral cohort were given the opportunity to practise interpreting with the aid of authentic material involving paramedic-patient interactions. Authentic audiovisual clips were posted online. Pauses and blank screens were inserted at points where the speakers took turns, to allow student interpreters to record their interpretation with minimal disruption. Recordings were anonymized and detailed feedback was given by language-specific markers following performance-based criteria. Formative feedback was passed on for students to reflect on their performance. Error analysis was carried out to measure students' performance when interpreting natural language. Student responses were gauged using pre- and post-intervention surveys. Students enjoyed being able to face actual challenges of interpreting 'in the setting', with the added advantage of receiving formative feedback that enabled them to reflect upon and improve their performance. One of the main challenges identified was that of interpreting informal paramedic discourse in a manner that was culturally appropriate, achieving pragmatic equivalence (Hale, 2014).
\end{abstract}

Keywords: Innovative interpreting pedagogies, audiovisual interpreting practice, idiomatic language, colloquial language, authentic paramedic language, pragmatic equivalence

\section{Introduction}

For today's interpreting graduates, there is a need for an ability to gather the information required for a task as it occurs, with the knowledge that an underlying understanding of genres and sociopragmatic norms is essential. A social constructivist approach to interpreter education has as its key the concept of learning through authentic action. Kiraly (2000) believes that teachers should create a scaffold for learning and allow the students to safely construct their knowledge gradually through practice. This fits in with the concept of 'situated learning' which was developed in the seminal work by Lave and Wenger (1991). Gee (1997, p. 243) defines situated learning as "specific patterns of experience tied to specific sorts of contexts." Ideally, student interpreters should be taken out of the classroom and into the societal context they may be expected to work in once they have graduated. Unfortunately, this is not always possible, since interpreters often work in situations of a highly confidential nature, and because of ethical and logistical 
constraints: student interpreters do not as yet have the skills required to work in specialized settings, and student observations in the setting are difficult to organize.

This paper presents an example of a classroom intervention which aimed to bring the setting into the classroom through the use of audiovisual resources for interpreting practice. The aim of the intervention was to assess the students' satisfaction with such resources, and also to provide them with feedback on their interpreting performance. One of the main challenges identified by the study was that of interpreting informal paramedic discourse in a culturally and pragmatically equivalent manner.

According to Pöchhacker (2011, p. 19) interpreting research methods can be said to mainly fall into the "Ask", "Watch" or "Record" categories, and "documentary material, often derived from technology-supported forms of observation such as audio or video recordings may be used to build singlecase or massive machine-readable corpora" (2011, p. 19-20). The data used for this study was derived from televised real-life documentaries showing paramedics at work. Hale and Napier (2013) describe classroom interventions as a way to test particular educational approaches. This classroom intervention not only fits with a situated learning approach, but also with the type of research referred to by Pöchhacker (2011) and Hale and Napier (2013). This paper will address the usefulness of audiovisual resources in the interpreter classroom. Features of paramedic discourse will be discussed, as will student and teacher evaluation of this learning tool. Findings include the need to incorporate a discussion on various types of medical discourse and appropriate strategies aimed at achieving pragmatic equivalence in interpretation.

\section{Background}

At the authors' university, health and legal interpreting students are exposed to expert performances through compulsory observation of experienced interpreters at work in health and legal settings. However, teaching staff felt that the students should also be exposed to authentic language used in those settings through an additional type of situated learning approach. Technological advances and the transition to an online Learning Management system were utilized to offer student interpreters practice in (semi-) authentic settings.

In the study reported on here, the situated learning approach resulted in student interpreters being able to practise interpreting of authentic language reflecting two entirely different communicative styles. The trainee health interpreters interpreted interactions between paramedics and patients, characterized by the use of colloquial language, where the focus was on achieving patient wellbeing and reassurance.

The authors' university offers language-neutral interpreter education (cf. also Hale \& Ozolins, 2014). Offering language-specific courses would fail to address the increasing need for interpreters in a multitude of languages in the increasingly multilingual society that is New Zealand today.

\subsection{Literature review}

This literature review will briefly focus on the different types of discourse involved, starting with approaches to interpreter education, which will be followed by an examination of health professional-patient language.

2.1.1 Approaches to interpreter education. In our institution, interpreter education follows the social constructivist, situated learning approach 
advocated by Gonzalez Davies (2004, 2012), Kiraly (1995, 1997, 2000) and Lave and Wenger (1991), with elements of the problem-based approach to learning outlined by Angelelli (2008). Liu's (2001) comparison of the performances of expert versus novice interpreters and her findings likewise point to the importance of real world experience in gaining interpreting expertise, through the acquisition of domain-specific skills. The authors agree with Ryu's suggestion that "the world outside the classroom doors" might be "a better learning arena in many areas" (2009, p. 256). However, involving trainee interpreters in situated learning 'in the real world' is not always feasible or safe for either students or the parties they might practise interpreting for. Therefore, the authors elected to use innovative situated learning technologies to enable both their classroom and online student cohorts to practise interpreting in authentic (virtual) contexts. Prior to the study reported on here, the situated learning approach had already involved trainee health interpreters' observing expert performances by practising interpreters in health settings. However, student interpreters were not able to practise interpreting in such authentic settings. Whilst lecturers provided semiauthentic audio-recorded material for students to practise with in the computer laboratory (or wherever they might be), students did not receive 'expert' language-specific feedback on their interpretation. Rather they relied on feedback from language peers.

The authors applied to their university for research funding to see whether using authentic audiovisual material, coupled with individual feedback, would address some of the limitations of the observation of expert performance and semi-authentic audio-only interpreting practice material.

In 1998, Shlesinger predicted interpreting scholars would have to await the advent of what she termed the "necessary technological breakthroughs" before they could have a corpus that might provide them with more than just the linguistic parameters $(1998$, p. 3). Current digital media enable us to not only access audiovisual corpora but also to adapt them to the interpreter classroom (Crezee, Burn \& Gailani, 2015). The use of such a corpus may be said to fit comfortably within a situated learning approach to interpreter training, as it allows student interpreters to practise with authentic material, where they see and hear language used in its original context. Seeing and hearing audiovisual and contextual cues enable student interpreters to deduce the meaning of language, which in turn enables them to render an accurate interpretation.

Situated learning approaches are ideally suited to helping student interpreters uncover some of the challenges of real world interpreting. In the study described here, interpreting authentic discourse used by paramedics in their interactions proved to be the main challenge. According to student comments, the informal nature of such discourse proved to be an issue that challenged any pre-conceived ideas about interpreter invisibility (Metzger, 1999) they might have held prior to participating.

2.1.2 Paramedic discourse. As stated, trainee interpreters in the studies reported on here were faced with the task of interpreting not just medical terms but also informal paramedic discourse.

2.1.3 Idiomatic language used by paramedics. Idiomatic language may be defined as colloquial everyday language that includes idioms and idiomatic expressions. Grant and Bauer (2004) provided not only a more restrictive definition of idioms per se, by focusing on their "non-compositional nature", but in the process they also created a "larger category of figuratives", comprising what was termed "the important group of expressions which have 
figurative meanings" (2004, p. 58). Both idioms and figuratives were the focus of the colloquial language used by paramedics in the audiovisual clips provided to trainee healthcare interpreters in one of the studies reported on here.

A number of authors (Antaki, 2007; Major \& Holmes, 2008; Pudlinski, 2005) have commented on the use of idiomatic and colloquial language by English-speaking health professionals. In describing the use of idioms by mental health practitioners, Antaki argues that "idiomatic talk in an institutional setting may be 'merely friendly' but not necessarily" (2007, p. 528 ), providing examples of how mental health practitioners use idiomatic language to summarize client accounts and get them to "express their agreement" (2007, p. 529). Antaki points out that idioms are easily recognizable to members of the in-group. The question is to what extent the student interpreters described in the current study may be considered 'full' members of the 'in-group' (Feng, 2014).

Major and Holmes (2008) outline characteristics of social talk used by nurses to describe healthcare procedures, which includes providing information, reasons, options and reassurance. Major and Holmes's discursive analysis showed evidence of the use of idiomatic expressions such as give me a buzz and steer clear of that. These are undoubtedly an element of what Major and Holmes describe as "the social talk which is so important to establishing empathy" (2008, p. 60).

In interacting with patients, paramedics may be said to have a number of communicative goals: they firstly need to quickly assess the patient's condition (triage), eliciting information from the patient or his/her family, as well as from any witnesses to events leading up to the current situation. Any information elicited is supplemented by investigations such as establishing vital signs (blood pressure, heart rate) and recorded, usually for the purpose of 'handing over' to medical personnel at the hospital emergency department (Iedema et al., 2012; Mitchison et al., 2012). Paramedics need to gather information, whilst also providing treatment and ensuring compliance by anxious patients, and colloquial language could be used to simultaneously communicate empathy and reassurance.

Communication in healthcare settings may be impacted by many possible risk factors (Schuster et al., 2010, p. 25), which may be further complicated by cross-linguistic and cross-cultural differences. How will trainee health interpreters interpret (in both senses of the word) strategies aimed at providing reassurance to anxious patients? Will they correctly identify idiomatic expressions and interpret these appropriately? As an added complication, not examined here, student interpreters from some cultural groups may be unsure how to interpret the colloquial language in a culturally appropriate way.

\section{Methodology}

The study described here used a mixed methods approach, involving assessment of interpreting performance using audiovisual recordings of authentic discourse-in-context which had been manipulated to allow for consecutive interpreting by students. Pre- and post-study surveys were used to gauge students' awareness of the type of discourse they were about to interpret and their response to practicing with unscripted audiovisual recordings rather than audio recordings scripted and recorded by their lecturers.

\subsection{Background to participants and practice material}

As stated above, the New Zealand and Australian healthcare systems are very 
similar in terms of organization and ideological underpinnings. In both countries, interactions between healthcare staff and patients are aimed at establishing a good rapport, and characterized by the use of idiomatic everyday language.

The study focused on natural idiomatic language used by paramedics interacting with the public. It also focused on students' awareness of the same, and their ability to recognize and interpret it at first attempt. Classroom discussions with healthcare interpreting students over the past two decades have shown that they encounter two main types of interpreting problems - the first one relating to medical terminology (as one would expect), but the second one relating to the use of everyday idiomatic language.

Audiovisual clips showing paramedics at work were chosen because the language used in the different clips referred to common healthcare conditions, which meant terminology was relatively easy to interpret for students who had already completed an introductory health interpreting course.

3.1.1 Error analysis in the work of trainee interpreters. The studies reported on here will focus mainly on trainee interpreters' ability to "grasp rapidly and convey the essential meaning of what is being said" (Gerver, Longley, Long, \& Lambert, 1989, p. 724) when interpreting idiomatic language from English as their additional language (EAL).

Barik (1969) employed a quite simple classification of interpreting errors comprised of omissions, additions and a category he described as "substitutions and errors" (p. 204-206) all of which the authors deemed relevant after an initial pre-analysis of students' interpreting performance. Within the category of semantic errors, Barik distinguished between mild and gross semantic errors $(1969$, p. 204$)$, ranging from mild through substantial to gross "phrasing changes" (1969, p. 205-207). In the studies reported on, external language assessors were asked to mark omissions, additions and changes in students' interpreting on the associated scripts, providing a translation of what had actually been said and how it constituted a change (if applicable). This enabled the authors to carry out an analysis similar to that described by Barik, since the involvement of external assessors did not allow for a more extensive analysis.

3.1.2 Researchers. One of the researchers was the course lecturer, while the other researcher was not in a student-teacher relationship with the students. Ethics approval for both studies was obtained from the University Ethics committee and it was suggested that the researcher who did not teach the students should be in charge of data collection.

3.1.3 Participants. Participants were all L2 English student interpreters representing a range of different languages including Mandarin, Cantonese, Russian, Samoan, Portuguese, Thai and Korean. Study 1 participants were all L2 English student interpreters in an advanced healthcare interpreting classroom. Participants had all successfully completed the introductory healthcare interpreting course in the previous semester of the academic year, acquiring a basic knowledge of anatomy, physiology and pathology of all major organ systems. They had also successfully completed the associated consecutive interpreting test focusing on a dialogue in medical settings. Since the audiovisual interpreting practice clips involved students interpreting consecutively after turns taken by ambulance paramedics and patients, students were well prepared for the type of interpreting and the medical terminology involved. 
3.1.4 Selection of audiovisual material. The researchers in the first study focused on identifying audiovisual recordings showing interactions between patients and healthcare professionals that were not of an overly specialist nature, yet contained a lot of idiomatic language. After surveying a range of recordings, including several based on in-hospital interactions, they opted to use scenes from an Australian series entitled Recruits: Paramedics. The program's accessibility through Educational Television (ETV) ensured its availability for educational purposes. The series follows newly graduated paramedics as they go out on their first assignments, mentored by more senior ambulance staff. Australian programs are regularly shown on New Zealand television, and usage and expressions are very similar. As mentioned previously, the Australian healthcare system is very similar to the New Zealand one. None of the 14 participants commented about the speakers being Australian at any stage, which may indicate that they were very familiar with both pronunciation and speaking style.

Episodes from the Recruits: Paramedics series were transcribed by a professional transcriber. Clips were chosen by selecting stretches of the transcript which contained a lot of natural idiomatic language that might prove a challenge to L2 English interpreting students. Each of the seven clips represented approximately five minutes of audiovisual interaction. It proved essential to keep the audiovisual practice clip at less than 10 minutes (after the insertion of silent pauses) as clips of over 10 minutes' duration proved difficult for students to download.

3.1.5 Assessment. Once students had interpreted the audiovisual tasks, the scripts, with the de-identified student recordings and associated audiovisual clips, were posted online using the learning management system available at the university. All these were posted on a site which was accessible only to the language assessors who normally assist with marking the student interpreting tests. The language assessors were asked to watch the audiovisual clips, listen to the student recordings and indicate on the script what sort of interpreting choices the learner made. They marked these as $\checkmark$ if a correct equivalent was used, as $\mathrm{O}$ if a word or phrase was omitted, and as $\mathrm{C}$ (for Change) if a word or phrase was interpreted differently. When the language assessors inserted a $\mathrm{C}$, they were asked to write a back translation in English of what the student interpreter actually said. The scripts with feedback were then provided to the learners, so they could benefit from the feedback.

Study participants completed one audiovisual task over seven consecutive weeks of the course, starting in week 3 and finishing in week 10 of the twelveweek semester. Study 2 participants completed one audiovisual task in each of weeks 3, 6 and 9 of the semester. Experience with study 1 had shown that students found one audiovisual task per week too much to cope with on top of their audio-only interpreting practice.

As mentioned, participants were asked to complete brief pre-test and post-test surveys. The main aim of the surveys was to gauge student interpreters' awareness of particular forms of authentic language use and the challenges this may pose to interpreters. A second aim was to gauge student interpreters' response to the use of audiovisual tasks based on authentic settings (e.g. paramedics and lawyers at work) as compared to the use of scripted, semi-authentic tasks recorded as audio tasks only (without the visual cues afforded by the audiovisual tasks). In both studies, scripts containing individual feedback from the markers were emailed to the participating students, but a copy was also printed and used for purposes of interpreting analysis. 


\section{Analysis}

4.0.1 Assessment feedback. The anonymous language assessors were asked to focus mainly on the way student interpreters had handled the idiomatic language. In the scripts given to the language assessors, such examples of idiomatic language had been italicized with a paraphrase of the meaning added between brackets.

As stated previously the language assessors were asked to provide very simple feedback to students, consisting only of 'correct interpretation', 'omission' or 'change' with a back translation in English and a verbatim rendering in the student's language written on to the script. All idiomatic expressions in the script were followed by a brief explanation of that expression in between brackets and printed in italics, so students could see what the expression actually meant and how they had interpreted it.

Idiomatic expressions from the scripts were then inserted into an Excel spreadsheet and for each expression on each clip, a comment was made as to how the student had interpreted the expression in question (correct paraphrase, omission or incorrect interpretation). Those that were changed were added into the Excel sheet to allow for further analysis as to the nature of the miscue: incorrect translation because student apparently misheard (e.g. "Master and apprentice" interpreted as "Mister"), literal translation of component elements of the idiom (which made no sense in the Target Language) or idiomatic expression, or interpretation of selected elements only, i.e. meaning lost. An example of the latter was "John was thrown in the deep end" interpreted as "John was thrown".

For this analysis, we mainly looked at expressions used by paramedics interacting with patients.

\subsection{Findings of analysis}

4.1.1 Pre- and post-test surveys. The pre- and post-test surveys both focused on very similar questions, as they aimed to establish how students felt about their awareness of and ability to interpret idiomatic language, as well as to gauge the effectiveness of audio or audiovisual recordings. Findings of the post-test survey suggested that students really valued the opportunity to practise interpreting idiomatic language with the aid of audiovisual clips.

4.1.2 Analysis of language use. Table 1 shows an overview of the use of idiomatic language by the various speakers in the audiovisual clips. Speakers included the narrator $(\mathrm{N})$, dispatchers, paramedics and patients or their family members. Paramedics could be heard speaking to the dispatchers, to each other, to the camera, and to patients or their family members. Table 1 shows the numbers of idiomatic expressions used by speakers. An analysis of the transcript of the audiovisual segment showed that idiomatic language used by paramedics fitted into the following taxonomy:

- Questions: Eliciting information from either patient or relatives/bystanders

- Instructions

- Softened representations of medical reality (SRMRs) 
Table 1. Overview of idiomatic expressions (IEs) used by various speakers

\begin{tabular}{|r|r|r|r|r|r|r|r|r|}
\hline Clip & Total & & & & Paramedic & Paramedic & \multicolumn{3}{|c|}{ Paramedic to patient } \\
\cline { 5 - 8 } & IEs & N & Patient & $\begin{array}{c}\text { Para } \\
\text { to } \\
\text { paramedic }\end{array}$ & camera & Questions & Instructions & SRMRs \\
\hline 1 & 12 & 5 & 0 & 0 & 1 & 1 & 2 & 3 \\
2 & 10 & 3 & 0 & 0 & 6 & 0 & 0 & 1 \\
3 & 14 & 8 & 1 & 1 & 4 & 0 & 0 & 0 \\
4 & 9 & 1 & 0 & 3 & 5 & 0 & 0 & 0 \\
5 & 21 & 5 & 0 & 0 & 9 & 0 & 1 & 1 \\
6 & 10 & 3 & 3 & 0 & 0 & 1 & 0 & 3 \\
7 & 21 & 6 & 0 & 1 & 0 & 0 & 0 & 7 \\
\hline All & $\mathbf{8 5}$ & $\mathbf{3 1}$ & $\mathbf{4}$ & $\mathbf{5}$ & $\mathbf{2 5}$ & $\mathbf{2}$ & $\mathbf{3}$ & $\mathbf{1 5}$ \\
\hline
\end{tabular}

Most idiomatic expressions consisted of between 5 and 7 words. Examples included: with no room for error, I'm still a bit sort of in the zone, still hasn't sunk in, keep an eye on her, she's a bit worked up, try to squeeze in a quick dinner, legs just went from under me.

Examples of idiomatic expressions comprising instructions included: You reckon you can give us a hand to get on the bed? Other examples of informal colloquial language used to elicit information included What has our young lady done? (speaking to an 85-year old female), followed by You let me know if you need anything more okay?

Softened representations of medical reality were used to both keep patients informed as to what was happening or about to happen, but also to provide reassurance. Examples where paramedics used informal colloquial softeners such as a bit and just included: you need to go into the hospital, get a bit of a chest $x$-ray and I just need you to hang in there alright?

Examples of three categories of interactions were found within the same utterance, as for instance in: I'm just going to pop this on your face, cause your breathing is pretty ordinary isn't it doll' and: We are just pulling up okay. Just keep coughing it up, you are doing really well okay? And Going to try and clean you up here a bit alright speaking to a patient with a serious episode of pneumonia complicated by swine flu. Another utterance aimed at both instructing and reassuring included: Okay, just straighten that leg up for me. You're alright, you don't move at all, you let me move you. Another paramedic said: You look like you might have done that other hip darling. That's how it's sort of looking to make the elderly patient aware that she had probably suffered (another) hip fracture.

Paramedics were using the word 'just' and verbs such as 'pop' to indicate that actions would take no time at all, thus seemingly trying to minimize such actions and reassure patients. Examples included: get a bit of an X-ray, there's quite a bit going on, she's a bit worked up. Colleagues and patients were addressed in very informal ways, with examples including: you're going good, buddy; you're alright, mate; our young lady; sweetie; darling and doll. Student interpreters almost invariably omitted such terms of address. Since we did not survey students about their interpreting choices, we can only surmise that they may have deemed these culturally inappropriate and thought it better to leave them out altogether.

Examples of the most commonly misinterpreted idiomatic expressions can be seen in Table 2. All those who misinterpreted pop this on your face failed to accurately convey the meaning of 'put something on your face quickly'. Students also had problems handling the expression a bit of time in the sense of a brief amount of time (30\% correct). This interpretation is not taking into account that in fact the expression a bit of time is often used to soften the fact that the process may in fact be somewhat lengthy. Such 
expressions are often used by nurses to reassure patients (Major \& Holmes, 2008). It is therefore somewhat concerning that trainee health interpreters do not get this meaning of doing something quickly, as the intended minimization attempt would have also been lost. It is also concerning that 'popping' something on was changed into taking something off.

In the case of a patient's car having been rear-ended, three of the students changed the meaning so that the situation was reversed and the victim was said to have run into the car in front of her.

Table 2. Idiomatic expressions omitted or changed by $>50 \%$ of participants

\begin{tabular}{|c|c|c|c|c|}
\hline $\begin{array}{l}\text { Idiomatic } \\
\text { expression }\end{array}$ & $\begin{array}{c}\text { Total } \\
\text { number of } \\
\text { students }\end{array}$ & Omitted & Changed & $\begin{array}{c}\text { Examples of incorrectly interpreted } \\
\text { phrases }\end{array}$ \\
\hline $\begin{array}{l}\text { You reckon you } \\
\text { can give us a } \\
\text { hand to get } \\
\text { onto the bed? }\end{array}$ & 14 & 5 & 3 & $\begin{array}{l}\text { give us your arm; give us one of your } \\
\text { hands. }\end{array}$ \\
\hline $\begin{array}{l}\text {...she's a bit } \\
\text { worked up... }\end{array}$ & 14 & 6 & 2 & $\begin{array}{l}\text {-should be able to recover with a good } \\
\text { night's rest; so it brought her to the } \\
\text { current }\end{array}$ \\
\hline $\begin{array}{l}\text { She was rear- } \\
\text { ended when the } \\
\text { car in front of } \\
\text { her stopped } \\
\text { suddenly }\end{array}$ & 13 & 3 & 6 & $\begin{array}{l}\text { she hit a car in front; she went into a } \\
\text { car; she hit the front; she lost her } \\
\text { direction; her car spin out as it been hit }\end{array}$ \\
\hline $\begin{array}{l}\text {...my legs just } \\
\text { went out from } \\
\text { under me... }\end{array}$ & 11 & 4 & 4 & $\begin{array}{l}\text { I think this side has no feelings; legs } \\
\text { stayed/went on; something went not } \\
\text { quite well; everything was blurry'. }\end{array}$ \\
\hline $\begin{array}{l}\text { Probably still } \\
\text { hasn't sunk in }\end{array}$ & 13 & $4^{*}$ & 7 & $\begin{array}{l}\text { too much happened today I think I will } \\
\text { slowly accept them; now starts slowly } \\
\text { realizing; have to slowly experience it }\end{array}$ \\
\hline $\begin{array}{l}\text { I will just pop } \\
\text { that on you }\end{array}$ & 12 & 3 & 4 & $\begin{array}{l}\text { Do you have any problems?; I'll take } \\
\text { this off; I'll just take out this thing into } \\
\text { this way; I'll take that out }\end{array}$ \\
\hline $\begin{array}{l}\text { thrown in the } \\
\text { deep end }\end{array}$ & 12 & 1 & 6 & $\begin{array}{l}\text { has experienced death; was right about } \\
\text { his job; has done a lot of good things in } \\
\text { a week; was put onto a day shift; has } \\
\text { been involved as much as possible; } \\
\text { 'has been thrown in day team. }\end{array}$ \\
\hline
\end{tabular}

*2 omitted; 2 inaudible mumbling

With regard to the expression it still hasn't sunk in, two students seemed to have mistaken the word 'sunk' for 'sun'. Another one said I will slowly accept them, and it should be noted that in spoken Chinese language, the verb 'accept' can also mean 'to understand'.

After completing the audiovisual clips, some students commented that they felt well-prepared to interpret medical terminology, but struggled to interpret some of the colloquialisms. At the end of the last clip, there was a comment by an experienced paramedic to the effect that the new recruit paramedic had been thrown in the deep end. This common colloquial expression was misinterpreted by $58 \%$ of students. In a sense, students themselves were thrown in the deep end with these idiomatic expressions and results suggested they needed more exposure to authentic everyday colloquial and idiomatic language.

\section{Discussion and conclusion}

In the study described here, student healthcare interpreters practised 
interpreting with audiovisual clips based on the interactions of ambulance paramedics with a range of patients. It is sometimes jokingly said that informality is the default mode of communication in Australia and New Zealand and the discourse of the paramedics certainly fell into this category, as they tried to establish rapport with their patients and get them to relax. Interpersonal features of their discourse included giving instructions, eliciting information and softening medical reality through the use of everyday idiomatic language. Most important of all, their discourse appeared natural and unscripted.

The findings demonstrated students' apparent lack of familiarity with idiomatic and colloquial language, both in terms of recognizing it as such, and being able to accurately guess its meaning, as well as cross-cultural issues relating to the acceptability of such language in the patient's culture. Several students commented afterwards that it would be unacceptable in their culture to address patients as doll, sweetie, mate, buddy or by their first name (as in the case of 85-year old Gwen). Some said they considered them culturally inappropriate and had felt omission was the best approach. While such terms of address can easily be left out without changing the meaning of the utterance, the same cannot be said for the omission of colloquialisms used to help make patients feel more relaxed about their situation. It might be that interpreting trainers need to make room in their training to cover this aspect of the language with trainees and its purpose, especially with those trainees aiming to become medical interpreters.

Limitations of the studies included small student numbers, and the fact that the language-neutral approach to interpreter education resulted in students recording their interpreting in a range of languages. The study showed that health interpreting students need to be exposed to authentic colloquial language used in context, and courses should include exposure to such language rather than only focusing on medical terminology. Student comments around the challenges of interpreting informal paramedic discourse in a culturally and pragmatically equivalent manner (Hale, 2014) could be incorporated into classroom discussions around interpreter invisibility (Metzger, 1999) and strategies for achieving pragmatic equivalence. Students' comments about these challenges also provide an argument for including classroom sessions focusing on different discourse genres within healthcare interpreting, and on appropriate interpreting strategies. It is obvious from Russell and Dunkley (2015) that trainee interpreters need to be prepared for a wide range of discourse types within healthcare settings.

The study showed that healthcare interpreting trainees did not appear to have time for any type of top-down textual analysis: they reacted to what they heard, only having time for a very quick bottom-up analysis. It would seem that students need as much audiovisual interpreting practice with authentic interactions as possible within budgetary and logistical constraints.

Situated learning approaches should include using authentic clips together with tasks which involve students watching at least one health-related real-life documentary per week. In New Zealand, Educational Television (ETV) allows teachers to request online recordings of documentaries and other programs of interest to students. Students can then log in to ETV using their university login and password and download and/or watch such programs to add further elements of situated learning to assist their development as lifelong learners.

This article reported on a research project involving healthcare interpreting students studying advanced healthcare interpreting at undergraduate level. The study involved a cohort of students with different language pairs in a language-neutral course. The project involved a situated 
learning approach which used authentic interpreting practice as well as preand post-study questionnaires. Both students and language assessors commented that they particularly appreciated having authentic practice material. Students especially enjoyed being able to face the actual challenges of interpreting 'in the setting' with the added advantage of receiving formative feedback enabling them to reflect on and improve their performance.

It is hoped that future research with trainee healthcare interpreters in similar situated learning environments will further contribute to our understanding of the 'best practice' for such students.

\section{References}

Angelelli, C. (2008). The role of the interpreter in the healthcare setting. In ValeroGarcés, C., \& Martin, A. (Eds.), Crossing borders in community interpreting: Definitions and dilemmas (pp. 147-164). Amsterdam: John Benjamins.

Antaki, C. (2007). Mental-health practitioners' use of idiomatic expressions in summarising clients' accounts. Journal of Pragmatics 39(3), 527-541.

Barik, H. (1969). A study in simultaneous interpretation. (Unpublished doctoral dissertation, University of North Carolina, USA).

Crezee, I., Burn, J. A., \& Gailani, N. (2015). Authentic audiovisual resources to actualise legal interpreting education. MONTI: Monographs in Translation and Interpreting, (7), 271-293.

Feng, H. (2014). A corpus-driven study of the use of Chinese translators' use of English collocations in commercial Chinese to English translation. (Unpublished doctoral dissertation, Auckland University of Technology, Auckland, New Zealand). Retrieved from http://aut.researchgateway.ac.nz/handle/10292/8004

Gee, J. P. (1997). Thinking, learning and reading: the situated sociocultural mind. In D. Kirshner \& J.A. Whitson (Eds.), Situated cognition: Social, semiotic and psychological perspectives (pp. 235-259). Mahwah, NJ: Erlbaum.

Gerver, D., Longley, P., Long, J., \& Lambert, S. (1989). Selection tests for trainee conference interpreters, Meta 34(4), 724-735.

Gonzalez Davies, M. (2004). Multiple voices in the translation classroom: activities, tasks and projects (Vol. 54). Amsterdam: John Benjamins.

Gonzalez Davies, M. (2012). Towards situated translation training: Bridging academic and professional approaches. Keynote presentation held at the Translation Studies Symposium Training Postgraduate Students for the Translation Profession: Didactic Implications and Research Opportunities, University of Auckland, Centre for Translation Studies and Interpreting, Auckland, New Zealand.

Grant, L., \& Bauer, L. (2004). Defining idioms: Are we barking up the wrong tree? Applied Linguistics 25(1), 38-61.

Hale, S. (2014). Interpreting culture. Dealing with cross-cultural issues in court interpreting. Perspectives. Studies in Translatology 22(3), 321-331.

Hale, S., \& Napier, J. (2013). Research methods in interpreting: A practical resource. London, England: Bloomsbury.

Hale, S., \& Ozolins, U. (2014). Monolingual short courses for language-specific accreditation: Can they work? A Sydney experience. The Interpreter and Translator Trainer 8(2), 217-239. DOI: 10.1080/1750399X.2014.929371

Iedema, R., Ball, C., Daly, B., Young, J., Green, T., Middleton, P., ... Comerford, D. (2012). Design and trial of a new ambulance-to-emergency department handover protocol: IMIST-AMBO. BMJ Quality \& Safety, 21, 627-633.

Kiraly, D. (1995). Pathways in translation. Kent, OH: Kent State University Press.

Kiraly, D. (1997). In search of new pathways for translator education'. In H. Drescher (Ed.), Transfer: Übersetzen - Dolmetschen - Interkulturalität. Funfzig jahre Fachbereich Angewandte Sprach - und Kulturwissenschaft de Johannis Gutenberg Universität Mainz im Germersheim (pp.135-152). Frankfurt am Main: Peter Lang.

Kiraly, D. (2000). A social constructivist approach to translator education: Empowerment from theory to practice. London, England: St. Jerome. 
Lave, J., \& Wenger, E. (1991). Situated learning: Legitimate peripheral participation. Cambridge, England: Cambridge University Press.

Lave, J., \& Wenger, E. (1994). Situated learning: Legitimate peripheral participation. American Ethnologist 21(4), 918-919.

Liu, M. (2001). Expertise in simultaneous interpreting: A working memory analysis. (Unpublished doctoral dissertation, University of Texas, Austin, Texas).

Major, G., \& Holmes, J. (2008). How do nurses describe health care procedures? Analysing nurse-patient interaction in a hospital ward. Australian Journal of Advanced Nursing 25(4), 58-70.

Metzger, M. (1999). Sign language interpreting: Deconstructing the myth of neutrality. Washington, DC: Gallaudet University Press.

Mitchison, D., Butow, P., Sze, M., Aldridge, L., Hui, R., Vardy, J., ... Goldstein, D. (2012). Prognostic communication preferences of migrant patients and their relatives. Psycho-Oncology 21(5), 496-504.

Pöchhacker, F. (2011). Researching interpreting. Advances in interpreting research: Inquiry in action 99, 5-25.

Pudlinski, C. (2005). The mitigation of advice: Interactional dilemmas of peers on a telephone support service. In C. Baker, M. Emmison \& A. First (Eds.), Calling for help: Language and social interaction in telephone headlines (pp.109-131). Amsterdam: John Benjamins.

Ryu, H. (2009). Designing situated learning experiences. In R. Hokyoung \& D. Parsons (Eds.), Innovative mobile learning: Techniques and technologies (pp.255-272). Hersey, NY: IGI Global.

Russell, D., \& Dunkley, J. (2015). Interview with a trailblazer. International Journal of Interpreter Education 7(1), 84-89.

Shlesinger, M. (1998). Corpus-based interpreting studies as an offshoot of corpus-base translation studies. Meta 43(4), 486-493.

Schuster, C. R., Schuster, P., \& Nykolyn, L. (2010). Communication for nurses: How to prevent harmful events and promote patient safety. Philadelphia, PA: F.A. Davis. 